\title{
OBITUARY
}

\section{CLARENCE OLDS SAPPINGTON \\ M.D., Dr.P.H.}

1889-1949

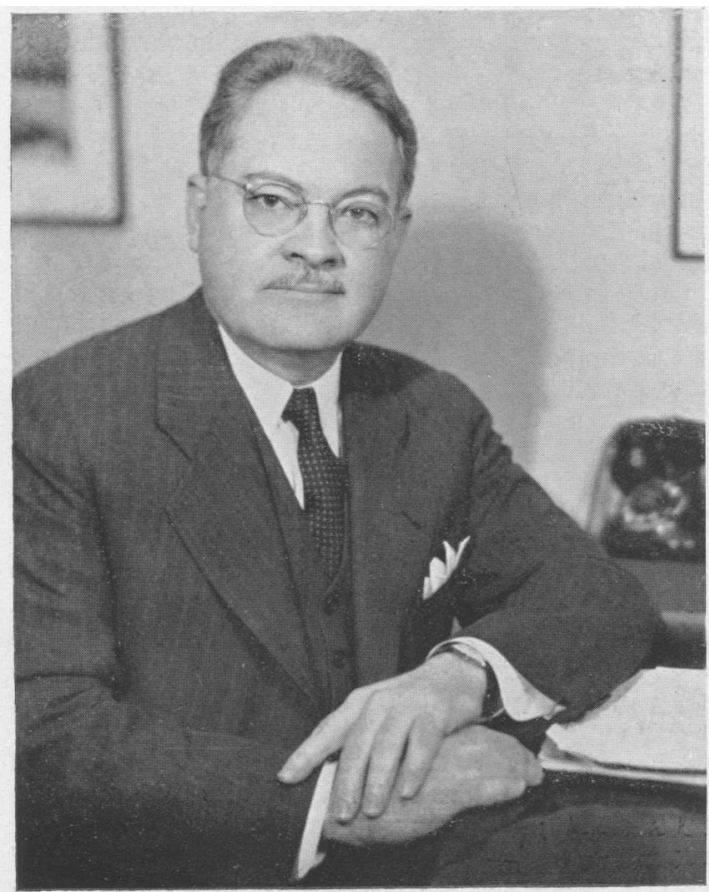

The sudden death of Dr. C. O. Sappington on November 6, 1949, came as a great shock to his many friends who work in industrial medicine, the more so in view of his seemingly eternal vitality.

Dr. Sappington's eminence in industrial medicine resulted from inherent capacities, sound basic training, and many years of active practice in the field. At the Harvard School of Public Health in 1924 he was the first American to receive the degree of Doctor of Public Health in Industrial Hygiene. Recognition of his achievements led to his being selected in 1939 as the first recipient of the William $\mathbf{S}$. Knudsen award for the most outstanding contribution to industrial medicine.

After serving as medical director of large industrial concerns in California, Dr. Sappington became Director of the Division of Industrial Health established in 1928 by the National Safety Council. The sound and wellinformed advice he gave to member companies of the Council caused him to be much in demand for consultations throughout the United States of America. His home was in Chicago, but his facility in lucid exposition led to his appointment as special lecturer on industrial medicine to some seven universities and medical schools in various States. Dr. Sappington's international interests were shown by his serving as delegate to the International Hygiene Congress in Dresden in 1930, the International Congress on Accidents and Industrial Diseases in Geneva in 1931, and again in Brussels in 1935.

Dr. Sa ington was best known as a consultant in the medico-l $i:$. id preventive aspects of occupational diseases, and as editor of Industrial Medicine and Surgery, published monthly in Chicago. Over the years he was a prolific writer on all phases of industrial health, having been the author of over 200 papers on these subjects. Of his three books, "Industrial HealthAssets and Liabilities" remains a most useful popular treatment of the subject, and "Essentials of Industrial Health" a comprehensive and authoritative textbook.

Among the organizations with which Dr. Sappington was closely associated were the American Association of Industrial Physicians and Surgeons, of which he had just been elected a director; the American Industrial Hygiene Association, president of its Chicago Section ; the Ramazzini Society ; the Central States Society of Industrial Medicine and Surgery, of which he was president. For the Industrial Hygiene Foundation of America, Dr. Sappington conducted a nation-wide survey of industrial health departments and of health problems concerning women in industry. The American Medical Association Council on Industrial Health had appointed him as executive officer of the Committee on Workmen's Compensation. Shortly before his death he was recognized as a specialist by the newly established American Board of Preventive Medicine and Public Health.

The extent of Dr. Sappington's contacts was disclosed in his column "Dr. Pilgrim " which appeared monthly in Industrial Medicine and Surgery. This chronicle gave an intimate insight into the wide diversity of persons and projects with which he was associated throughout his tremendously productive life. Dr. Sappington was always good company; a genial man, who kept his balance and his kindly disposition even when he lost his only son in the second world war. He loved good music and played the piano and the bass viol, accomplishments which he kept up throughout his life. Both the warmth of his friendship and the injection of his dynamic personality into all that he did will be greatly missed by his friends everywhere.

WARren A. COOK 